\title{
The Economic Attractiveness of Electric Vehicles in Brazil: The Importance of Incentive Policies
}

\author{
Ana Carolina Cordeiro \\ Federal Fluminense University \\ Luciano Losekann \\ Federal Fluminense University
}

\begin{abstract}
Electric vehicles (EV) are emerging as less polluting alternatives to internal combustion engine vehicles (ICE). Within the context of the climate change, electric vehicles (EV) become an option for the decarbonization of the transport sector. This paper evaluates the economic attractiveness of a battery electric vehicle (BEV) and a hybrid electric vehicle (HEV) compared to an internal combustion engine vehicle (ICE) in Brazil. Considering the specific characteristics of the Brazilian market, such as the welldeveloped biofuels sector and the preference for vehicles with low acquisition value, EV adoption tends to be slower in Brazil. In addition, we emphasize the importance of incentive policies to encourage the adoption of electric vehicles (EV) in Brazil, considering the different profiles of potential EV adopters.
\end{abstract}

Keywords: electric vehicles, diffusion, incentive policies

\section{INTRODUCTION}

The concern about the climate effects of greenhouse gas emissions has motivated the search for less polluting alternatives in the transport sector. Electric vehicles (EVs) diffusion is one of the vectors promoting the decarbonization of the energy matrix. In addition to the climatic aspects, the diffusion of electric vehicles could help to achieve other objectives, such as the reduction of oil dependence in importing countries, the reduction of noise in urban areas, as these vehicles have quiet operation, and improved air quality. Thus, this paper will propose a comparison between a battery electric vehicle (BEV) and an internal combustion engine vehicle (ICE) and hybrid electric vehicles (HEV) and the same internal combustion engine vehicle (ICE). We present the difference between the economic attractiveness of these types of vehicles in Brazil. Furthermore, the paper highlight the importance of policies to encourage adoption of electric vehicles in Brazil, considering the different profiles of potential adopters of this technology. For the analysis, we created four simplified profiles of potential EV adopters.

It is important to note that there are challenges on the EVs diffusion. We can highlight the high cost of batteries and the lack of charging infrastructure that implies in range anxiety that is the concern of the owners with the existence of charging stations properly distributed geographically (Bonges and Lusk, 2016). Regarding these issues, there is an interdependence between EV adoption and charging station investment. This is because encouraging the adoption of electric vehicles by subsidizing the purchase 
generates effects on the development of charging infrastructure, just as the incentive to build charging stations generates impacts on the purchase of new vehicles (Li et al., 2017).

\section{THE BRAZILIAN CASE}

Brazil has already had an experience of widespread diffusion of alternative automotive technology. After the oil crisis, Brazil adopted in 1975 the National Ethanol Program called Pró-Álcool. The Fiat 147 was the first ethanol car in Brazil in 1979. The Brazilian state was very interventionist and adopted protectionist measures against imports and ethanol cars were successful. In 1986, the price of the barrel of oil in the international market reduced, which hampered the programs of substitution of fossil energy. In 1990 since cheap oil made it unfeasible to keep subsidies on fuel ethanol, the Pro-Álcool program was discontinued (See Figure 1).

\section{FIGURE 1 \\ DIFFUSION OF ETHANOL CARS}

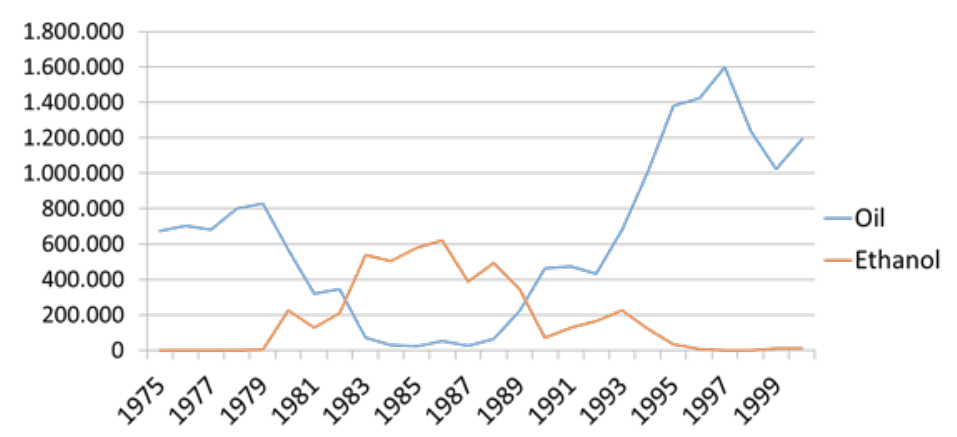

Source: Own elaboration based on ANFAVEA (2018).

Regarding the flex-fuel cars, this diffusion was facilitated by two factors. The Brazilian market has the characteristic of adding ethanol to gasoline, which generates the need for mechanical adjustments of the engines. Thus, Brazil already had adapted car engines. In addition, the country already had an ethanol distribution and marketing infrastructure. Therefore, the flex fuel car did not face difficulties to gain the largest market share. In March 2003, Volkswagen started selling Gol 1.6, the first flex fuel car in Brazil.

It is important to note that there is a difference between the diffusion of ethanol and flex-fuel cars and electric vehicles. Ethanol and flex-fuel cars use the same supply infrastructure, which is not the case of plug-in electric vehicles that need a charging infrastructure that does not exist.

Brazil has specific characteristics that could influence the way in which EVs will be introduced. Firstly, Brazil has an electric matrix of predominantly renewable origin (BEN, 2020). Figure 2 shows the domestic supply of electricity in Brazil in 2019. 
FIGURE 2

DOMESTIC ELECTRICITY SUPPLY BY SOURCE

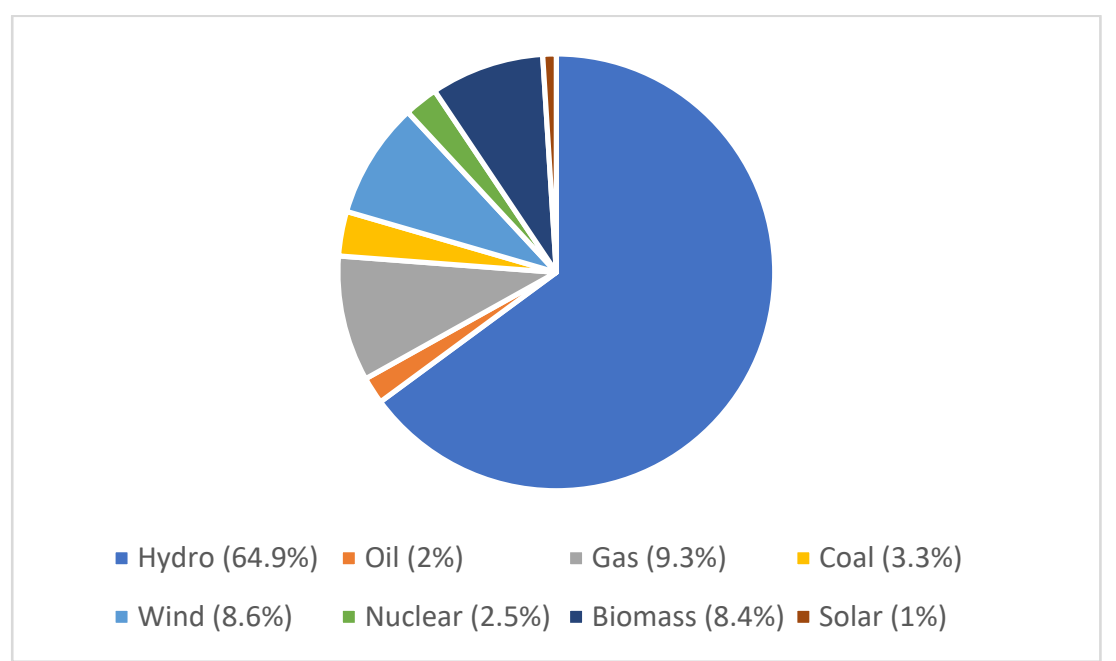

Notes: Hydro includes electricity imports; Biomass includes firewood, sugarcane bagasse, black-liquor and other primary sources; Coal includes coke oven gas.

Source: BEN (2020).

The Brazilian electric matrix is mostly renewable and this characteristic can be an advantage in the EVs diffusion since it allows electrification of transport to imply lower emissions. The country is very dependent on road transport and the use of EVs could significantly reduce the country's greenhouse gas emissions. On the other hand, the significant share of energy from biomass also favors the use of biofuels since they are renewable sources and also reduce greenhouse gas emissions.

Brazil has a well-developed biofuels sector and more than $80 \%$ of all licensing of cars is flex-fuel, that is, they can be fueled with gasoline and ethanol, as we can see in TABLE 1.

TABLE 1

TOTAL LICENSING OF CARS BY FUEL IN 2018

\begin{tabular}{|l|c|c|}
\hline Type of Fuel & Number of Vehicles & Market Share \\
\hline Gasoline & 81,932 & $3,31 \%$ \\
\hline Electric & 3,970 & $0,16 \%$ \\
\hline Flex Fuel & $2,168,176$ & $87,59 \%$ \\
\hline Diesel & 221,278 & $8,94 \%$ \\
\hline
\end{tabular}

Source: ANFAVEA (2019).

The possibility of using ethanol makes the need for EVs less relevant in reducing greenhouse gas emissions, even though ethanol reduces emissions to a lesser extent. Furthermore, the high cost of batteries makes it difficult to adopt these vehicles in developing countries. Brazil has a concentration of the fleet in low acquisition value cars, a segment in which EVs have less competitiveness. The lack of charging infrastructure is also a challenge in a country with continental dimensions. Thus, public policies play an important role in promoting the adoption of electric vehicles.

\section{METHODS}

In order to evaluate the attractiveness of the acquisition of an electric vehicle in Brazil, we will make an economic feasibility study comparing the acquisition of battery electric vehicle (BEV), hybrid electric 
vehicle (HEV) and an internal combustion engine vehicle (ICE). In this paper, we consider two types of EVs, the Battery Electric Vehicle (BEV) and the Hybrid Electric Vehicle (HEV). BEVs are entirely powered by batteries. They have a storage system without the possibility of on-board electricity generation. The external energy supply is realized by a charging process of plugging a battery directly into the electricity grid. HEVs uses a main internal combustion engine and an electric motor in order to increase the efficiency of the vehicle. HEVs generates less emissions than similar conventional vehicles. The external energy input is fossil energy for an internal combustion engine. The energy recuperation of the braking process is only used to charge the battery. HEVs cannot be plugged in to the electricity grid (Ajanovic, 2015).

In the feasibility study, we compared in a cash flow a Toyota Corolla 1.8 Gli (ICE) with a Toyota Prius (HEV) and with a Nissan Leaf (BEV). From the INMETRO data, we collected the energy consumption data of Toyota Corolla and Toyota Prius. From U.S. Department of Energy and the U.S. Environmental Protection Agency data on energy consumption, we consider an approximation of the mileage values per liter for the Nissan Leaf that a gallon of gasoline is equivalent to $33.7 \mathrm{kWh}$. We assume that the consumer lives in Rio de Janeiro and drives 15,000 kilometers per year in the city.

In addition, we collect the resale prices provided by the FIPE Table (Institute for Economic Research) from 2015 to 2018 for the Toyota Prius and Toyota Corolla Gli 1.8 vehicles. Since the Nissan Leaf only started to be sold in Brazil in the year 2019, the depreciation rates of this vehicle were calculated from the resale values in the United States from 2015 to 2018 provided by Kelley Blue Book. These depreciation rates were applied to the vehicle acquisition value in Brazil in 2019.

TABLE 2

PURCHASE PRICE, FUEL SUPPLY AND RESALE PRICE

\begin{tabular}{|c|c|c|c|}
\hline Vehicle & Toyota Corolla & Toyota Prius & Nissan Lief \\
\hline Purchase Price & $\mathrm{R} \$ 90.900,00$ & $\mathrm{R} \$ 125.450,00$ & $\mathrm{R} \$ 180.000,00$ \\
\hline Fuel Supply - City (km/l) & 11,4 & 18,9 & 53,14 \\
\hline Resale Price after 4 years & $\mathrm{R} \$ 62.618,00$ & $\mathrm{R} \$ 84.142,00$ & $\mathrm{R} \$ 73.716,57$ \\
\hline
\end{tabular}

Source: INMETRO, U.S. Department of Energy, the U.S. Environmental Protection Agency, FIPE and Kelley Blue Book.

We present a cash flow, considering the acquisition value, refueling or charging costs and its resale value. We consider a consumer who buys his vehicle, drives 15,000 kilometers per year and resells after four years. We consider that the price of gasoline will remain constant for the next four years. We assume the price of gasoline as $\mathrm{R} \$ 5.13$ per liter, which is the average of prices charged from $10 / 28 / 2018$ to 11/03/2018 given by the National Petroleum Agency (ANP).

In Rio de Janeiro, EV consumers face difficulties in finding charging stations. Therefore, we assume that the consumer charges his vehicle at home at night. The charging time of the Nissan Leaf 2018 is 8 hours at $240 \mathrm{v}$. Thus, we considered the residential tariff of $\mathrm{R} \$ 0.575$ per KWh provided by the National Agency of Energy Electricity (ANEEL) in 2018. In these conditions, the fuel cost with a Toyota Corolla is $\mathrm{R} \$ 6,743.42$ and with a Toyota Prius is $\mathrm{R} \$ 4,067.46$ per year. The discount rate used for cash flows is $10 \%$.

TABLE 3

\section{COMPARISON BETWEEN TOYOTA PRIUS AND TOYOTA COROLLA}

\section{Toyota Prius x Toyota Corolla}

\begin{tabular}{|c|c|c|c|c|c|}
\hline & $\mathbf{0}$ & $\mathbf{1}$ & $\mathbf{2}$ & $\mathbf{3}$ & $\mathbf{4}$ \\
\hline Purchase Price/ Resale Price & $-\mathrm{R} \$ 34,550.00$ & $\mathrm{R} \$ 0.00$ & $\mathrm{R} \$ 0.00$ & $\mathrm{R} \$ 0.00$ & $\mathrm{R} \$ 19,524.00$ \\
\hline Fuel Economy in R & & $\mathrm{R} \$ 2,675.96$ & $\mathrm{R} \$ 2,675.96$ & $\mathrm{R} \$ 2,675.96$ & $\mathrm{R} \$ 2,675.96$ \\
\hline Cash Flow Results & $-\mathrm{R} \$ 34,550.00$ & $\mathrm{R} \$ 2,675.96$ & $\mathrm{R} \$ 2,675.96$ & $\mathrm{R} \$ 2,675.96$ & $\mathrm{R} \$ 22,199.96$ \\
\hline Net Present Value & $-\mathrm{R} \$ 12,732.41$ & \multicolumn{3}{|l}{}
\end{tabular}


The Table 3 identifies the cost differences between the Toyota Corolla and the Toyota Prius. At the time of purchase, the buyer spends an additional $\mathrm{R} \$ 34,550.00$ when buying a Toyota Prius. On the other hand, the Toyota Prius allows savings of R $\$ 2,674.96$ annually. However, in four years, these savings are not enough for HEV to be a better option economically, as can be seen from the net present value. The same comparison can also be made for the case of a BEV.

\section{TABLE 4 \\ COMPARISON BETWEEN NISSAN LEAF AND TOYOTA COROLLA}

Nissan Leaf $\mathbf{x}$ Toyota Corolla
\begin{tabular}{|c|c|c|c|c|c|}
\hline & $\mathbf{0}$ & $\mathbf{1}$ & $\mathbf{2}$ & $\mathbf{3}$ & $\mathbf{4}$ \\
\hline Purchase Price/ Resale Price & $-\mathrm{R} \$ 89,100.00$ & $\mathrm{R} \$ 0.00$ & $\mathrm{R} \$ 0.00$ & $\mathrm{R} \$ 0.00$ & $\mathrm{R} \$ 11,098.57$ \\
\hline Fuel Economy in R $\$$ & & $\mathrm{R} \$ 5,126.23$ & $\mathrm{R} \$ 5,126.23$ & $\mathrm{R} \$ 5,126.23$ & $\mathrm{R} \$ 5,126.23$ \\
\hline Cash Flow Results & $-\mathrm{R} \$ 34,550.00$ & $\mathrm{R} \$ 5,126.23$ & $\mathrm{R} \$ 5,126.23$ & $\mathrm{R} \$ 5,126.23$ & $\mathrm{R} \$ 16,224.81$ \\
\hline Net Present Value & $-\mathrm{R} \$ 65,270.06$ & & &
\end{tabular}

Although the annual fuel economy almost doubles, compared to the fuel economy provided by the HEV, the purchase price makes the option to buy a BEV less economically advantageous. In addition, the low resale value due to the depreciation of the battery impairs the attractiveness of these vehicles, as shown by the net present value. These results of these cash flows can be interpreted as the amount of subsidy needed to enable the diffusion of BEVs and HEVs.

\section{RESULTS}

The results of this study concluded that the fuel economy afforded by the HEV Toyota Prius is not enough to make the vehicle economically attractive due to the high value of the vehicle's acquisition. The same goes for the Nissan Leaf, the BEV reduces consumer spending because charging with electricity is cheaper than spending on gasoline and BEVs are more efficient. However, the high purchase price makes the vehicle even less attractive than the Toyota Prius.

It would be necessary to drive about $37,515.48 \mathrm{~km}$ per year so that the consumer would be neutral between a Toyota Corolla and a Toyota Prius under the conditions considered in the study. In the case of the Nissan Leaf, it would require an even bigger run, a total of 75,251.24 km per year.

We can interpret the net present value in these cases as the amount of subsidy needed to make these vehicles attractive. However, these subsidy amounts are very expensive, not making this policy feasible on a large scale. Therefore, policies in different areas would be necessary to make these vehicles attractive. As incentive policies we can highlight purchase subsidies, tax exemption, free parking, permission to use exclusive expressways and especially the construction of charging infrastructure, reducing the problem of range anxiety.

Consumers with higher incomes and who have a need to travel long distances tend to have more incentive to adopt electric cars. Based on the results of the feasibility study flow, we create a framework with profiles of potential EV adopters. We identify which profiles are the most likely to be EV consumers and which policies could be applied. We simplified vehicle consumer profiles according to two characteristics: purchasing power and mileage driven. This framework can help to understand in which market niches the adoption incentive policies can be more effective. 
FIGURE 3

PROFILES OF POTENTIAL EV ADOPTERS

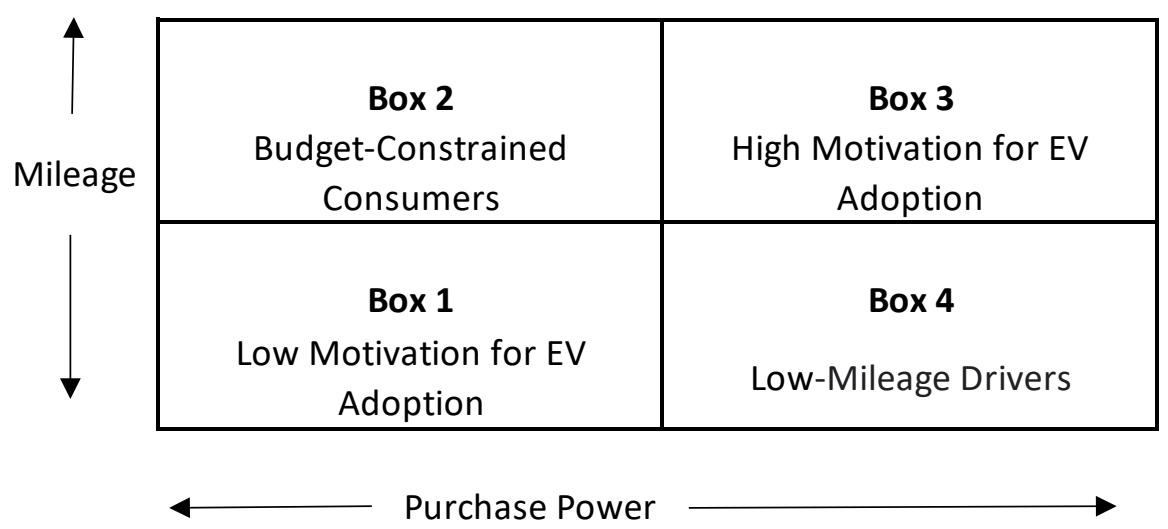

Box 1 consumers have low motivation to buy an EV, as they do not have purchasing power and do not travel long distances, which does not allow the fuel economy provided by EVs to be advantageous. Therefore, a large amount of subsidies is needed to make these vehicles attractive to this portion of consumers.

Box 2 consumers have a budget constraint, but they travel long distances with their vehicles. Box 2 can include taxi drivers and drivers who use mobility sharing apps such as Uber. Despite not having high purchase power to buy an EV, this potential consumer would have great fuel savings if they adopted an EV, considering the distance they travel daily. To encourage this type of consumer, policymakers should adopt incentives to build charging infrastructure that can reduce range anxiety.

In addition, in the case of taxi and Uber drivers, incentive policies must consider the need for superchargers. This is because, if the driver needs to charge the EV, the charging time implies a loss of work time and income.

Box 3 consumers would be the potential consumers with the greatest motivations for EV adoption, since they have purchase power and travel long distances. Considering that these potential consumers have a greater possibility of spending on the purchase of a vehicle, non-monetary policies could become attractive to this individual. Since they cover many kilometers, they benefit from the fuel economy provided. However, these consumers also face problems at the time of purchase, such as reach anxiety. Thus, policies to encourage the construction of charging infrastructure would be important for this consumer (in particular, the wide availability of superchargers). Furthermore, free parking spaces and the use of express lanes on highways could be effective incentives for this market niche.

Box 4 consumers do not travel long miles, but they have the purchase power to buy an EV. Thus, nonmonetary incentives could reach these potential consumers. As already mentioned, we can highlight as examples the free parking spaces and the use of express lanes on highways. It is important to note that environmental awareness can become an incentive for this consumer, as EVs reduce greenhouse gas emissions.

In addition to the measures mentioned above, we should mention the carbon tax, that is a taxation per ton of carbon emitted. This measure would reach all profiles of potential adopters, but could be especially effective for budget-constrained consumers. This is because these consumers would not want to be taxed for carbon emissions, and may view EVs as a possibility to avoid this tax.

\section{CONCLUSIONS}

The specific characteristics of the Brazilian market will make the EV diffusion in this country distinct from the others. As the biofuels sector is well-developed and vehicles with low acquisition value are the majority of sales in the country, EV adoption tends to be slower in Brazil. 
The current Brazilian scenario is not attractive for the acquisition of BEVs and HEVs. The feasibility analysis shows that large amounts of subsidy are needed to allow the EV diffusion. We made a simplified framework with four boxes of consumer profiles according to budget constraints and car usage needs. It is important to note that even though the consumer has no budget restriction to purchase a vehicle and uses the vehicle for long-distance travel, policymakers need to adopt incentive policies for these potential consumers to become EV buyers. This is because under the current purchase conditions in Brazil, EV is not attractive, even though it provides fuel savings and brings benefits such as the reduction of greenhouse gas emissions, reduction of noise and air pollution.

However, the Brazilian market may experience particular solutions such as hybrid or electric vehicles that have recalibrated auxiliary combustion engines for the use of ethanol. In addition, EVs may have niche markets in certain areas that have a greater incentive to adopt them, such as urban centers with poor air quality. Thus, we expect a late diffusion of electric vehicles and the coexistence of different automotive technologies in the coming years.

\section{REFERENCES}

Ajanovic, A. (2015). The future of electric vehicles: Prospects and impediments. Wiley Interdisciplinary Reviews: Energy and Environment, 4(6), 521-536.

ANFAVEA - Associação Nacional dos Fabricantes de Veículos Automotores. (2018). Anuário Estatístico 2018. Retrieved from http://www.anfavea.com.br/anuario.html

ANFAVEA - Associação Nacional dos Fabricantes de Veículos Automotores. (2019). Anuário Estatístico 2019. Retrieved from http://www.anfavea.com.br/anuario.html

Brazilian Energy Balance. (2020). Empresa de Pesquisa Energética. Retrieved from https://www.epe.gov.br/pt/publicacoes-dados-abertos/publicacoes/balanco-energetico-nacionalben

Bonges, H.A., \& Lusk, A.C. (2016). Addressing electric vehicle (EV) sales and range anxiety through parking layout, policy and regulation. Transportation Research Part A: Policy and Practice, 83, 63-73.

Consoni, F.L., de Oliveira, A., Barassa, E., Martínez, J., Marques, M.de.C., \& Bermudez, T. (2018). Estudo de Governança e Políticas Públicas para Veículos Elétricos. Projeto Sistemas de Propulsão Eficiente - PROMOB-e (Projeto de Cooperação Técnica Bilateral Entre a Secretaria de Desenvolvimento e Competitividade Industrial - SDCI/MDIC e a Cooperação Alemã Para o Desenvolvimento Sustentável (GIZ), 124.

Egbue, O., \& Long, S. (2012). Barriers to widespread adoption of electric vehicles: An analysis of consumer attitudes and perceptions. Energy Policy, 48, 717-729.

Fontaínhas, J., Cunha, J., \& Ferreira, P. (2016). Is investing in an electric car worthwhile from a consumers' perspective? Energy, 115, 1459-1477. https://doi.org/10.1016/j.energy.2016.05.075

Li, S., Tong, L., Xing, J., \& Zhou, Y. (2017). The Market for Electric Vehicles: Indirect Network Effects and Policy Design. Journal of the Association of Environmental and Resource Economists, 4(1). 